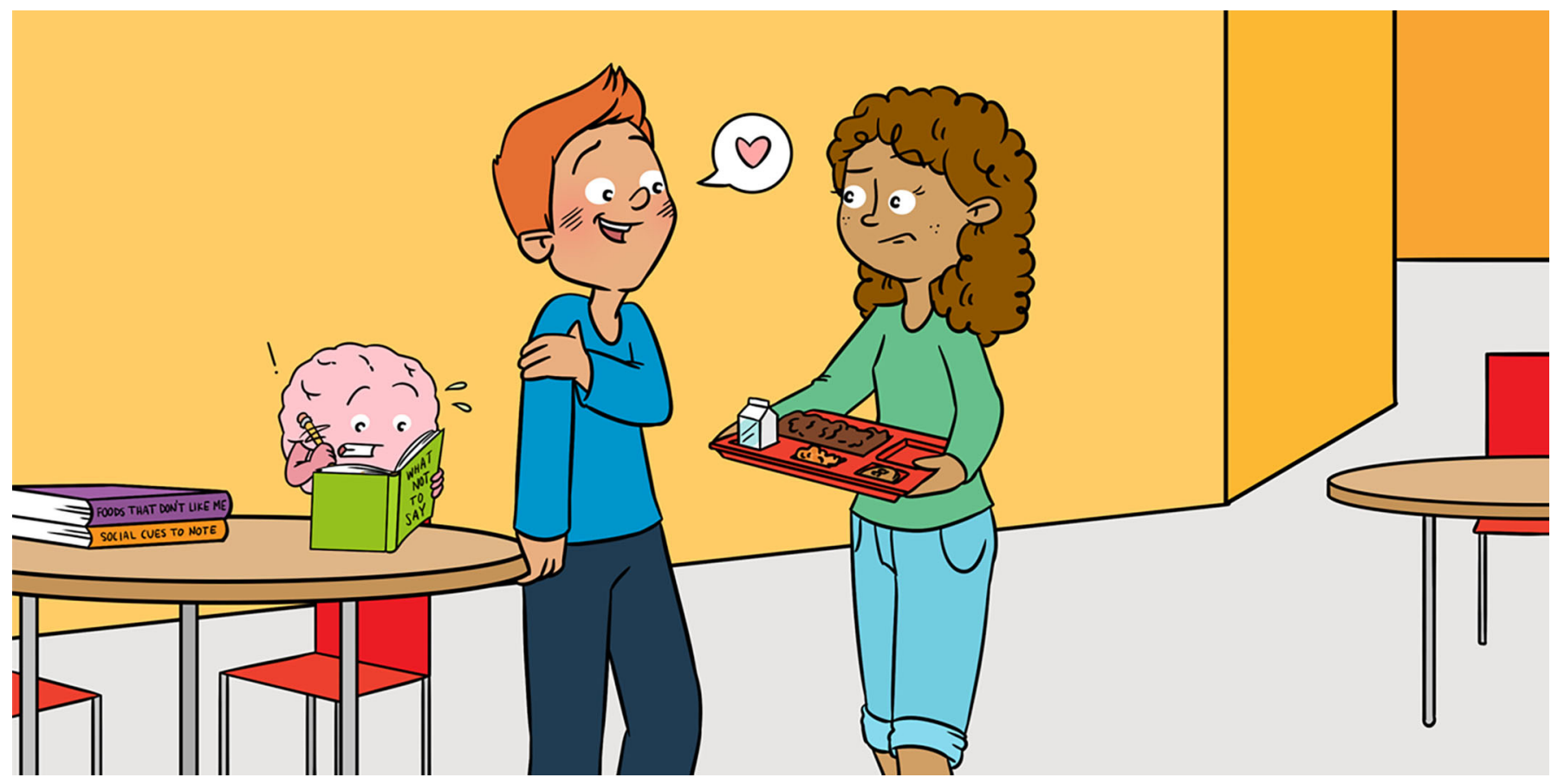

\title{
NEUROPLASTICITY: THE BRAIN CHANGES OVER TIME!
}

\section{Daniel Menezes Guimarães ${ }^{1 *}$, Bruna Valério-Gomes ${ }^{1}$ and Roberto Lent ${ }^{1,2}$}

${ }^{1}$ Laboratory of Neuroplasticity, Institute of Biomedical Sciences, Federal University of Rio de Janeiro, Rio de Janeiro, Brazil

${ }^{2}$ D'Or Institute for Research and Education, Rio de Janeiro, Brazil

YOUNG REVIEWERS:

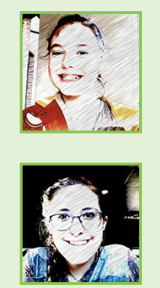

ASHLEY

AGE: 12

SAMANTHA

AGE: 15
You might not expect it, but the brain is always changing-it adapts itself to good and bad life experiences. We call this neuroplasticity. Although neuroplasticity usually helps us cope with problems, sometimes things go wrong, and the changes produced by neuroplasticity are harmful to the person. In this article, we cover two cases of neuroplasticity, one positive and one harmful. The positive one is about changes that happen when we are young and have good social experiences. The harmful one is about phantom limb syndrome, a strange phenomenon felt by amputees in their limbs and organs ... that no longer exist!

\section{WHAT IS NEUROPLASTICITY?}

We have all heard sentences, such as "The brain is a complex structure!" or "The brain commands all body functions!" but what fewer of us know is that the brain is not sitting there unchanging inside our skulls. It is always adapting to all sorts of different things 


\section{NEUROPLASTICITY}

Brain's ability to change its structure and function in response to life's events.

\section{MALADAPTIVE}

PLASTICITY

A harmful form of plasticity, such as the one that occurs in the phantom limb syndrome.

\section{SOCIAL COGNITION} SYSTEM

Set of skills and brain regions that are responsible for both understanding social rules and guiding our social behavior.

\section{CRITICAL PERIOD}

Time frame where the development of some regions of the brain and learning are enhanced.

\section{NEURON}

[NUR-AAN]

One of the many cell types making up the brain. Neurons connect to one another forming circuits, similar to train tracks. This is how information travels in the brain.

MYELINATION

[MAI-UH-LUH-NEI-SHN]

A process in which parts of the neuron are covered by membranes of a substance called myelin. Myelin functions like the rubber cover of electric wires, and it increases the speed by which information goes from one neuron to another. and situations. After you finish reading this article, we guarantee that your brain will be different!

The brain changes itself through a process called neuroplasticity. Let us decode this word. Neuroplasticity is a combination of two terms: neuro and plasticity. When we are talking about something related to the brain, we use the prefix neuro. The second term, plasticity, refers to the fact that the brain is always transforming itself. When you meet someone or learn a new fact, your brain changes its structure and function. The environment can change our brains, even if we are not aware of it. Some events change the way brain cells communicate with one another, by strengthening or weakening this communication. Other events will shape how the brain interprets things. All these changes end up modifying our behaviors!

Before moving on to the examples, we must consider two issues. First, neuroplasticity changes with age. As we grow older, the brain continues to find different ways of dealing with new things and situations [1, 2]. The ability to do this is related to the health of the brain. Why are older people who have always exercised and read a lot of engaging books less forgetful of things? Because an active, healthy brain can store mental resources that can be used, when it gets older, to modify itself. The second issue we must consider is that some neuroplastic events may not be helpful to us and may even be extremely harmful! This is what we call maladaptive plasticity [3].

\section{SOCIAL EXPERIENCES AND NEUROPLASTICITY}

So, we know that we must always try to practice engaging activities to enhance the brain's abilities, and that this will be very important if we want to maintain healthy brains as we get older. But are there any benefits of neuroplasticity for a younger brain? The answer is a definite YES! Scientists have found that there are certain time frames in our lives during which learning and brain development are strengthened. This is true for various systems, such as the visual system, and even for more complex ones, such as the social cognition system, which is the group of brain regions that helps us understand social information. We call these moments of heightened plasticity critical periods.

There are critical periods for neuroplasticity, too. As our first example, we will see how the environment influences social learning in a critical period during adolescence. First, let us dive for a moment into the brain's microscopical structure.

The brain is made up of many nerve cells, called neurons. In almost every region of the brain, the neurons undergo myelination, which involves the envelopment of neurons by a fatty (rich in lipids) membrane called myelin. Myelination greatly increases the efficiency of the brain's work. However, the critical period for myelination of 
neurons differs among brain regions. The part of the brain that helps us make sense of emotions, memory, and social information, called the medial prefrontal cortex ( $\mathrm{mPFC}$ ), is one of the last regions to myelinate. Myelination of the MPFC takes place during adolescence.

Adolescence is a difficult period in the development of our social abilities because it is the time when we start interacting more closely with friends and adults. Our brains must deal with a huge amount of social information during this period, as we ask questions like, "Who is my crush?" or "How should I talk to him/her and ask him/her out?" To navigate these situations, the brain's neurons must talk amongst themselves in complex neural circuits, to help a person navigate the social world. Everything needs to be working if we expect to manage these situations appropriately.

The problem is that we are not born ready for such interactions. Although the brain cells and the circuits are all there, we first need to improve these circuits and optimize their functioning.

Not so long ago, scientists discovered that, during adolescence, something triggers the myelination of neurons in the MPFC, and this helps us to better deal with social situations. Interesting fact: the event that triggers this process of myelination is social interaction! To make this clear: if you want to be good at social interaction, you must first interact! This is one of those cases where "practice makes perfection." Recent evidence shows that, between the ages of 15-20, the brain is at its peak potential to transform itself [4]. Remember the critical period? We know that if we do not engage in social experiences during our adolescence, the circuits in the mPFC will not myelinate, and this will affect our entire lives, post-adolescence.

Researchers have shown that if a juvenile mouse is deprived of social contact, it will avoid interacting with other mice [5]. Social experience during this critical period is so important that, even if the isolated animal is later housed with other mice, it will not regain its normal behavior. So, once the window closes, if there was a lack of appropriate social experiences, social behavior is forever changed.

\section{SYNDROME}

Condition where an amputee still feels sensations from the missing limb or organ. Although not always, it can be a painful sensation.

\section{A TALE OF PHANTOMS AND MALADAPTIVE PLASTICITY}

Wars and diseases can cause many terrible consequences, including the amputation of a limb. Amputation is a sad condition, but it can be also spooky. Some people who have had limbs amputated have the physical sensation that the amputated part still exists. This ghostly experience is part of a condition called phantom limb syndrome, which consists of feeling pain, movement, and other sensations coming from an amputated limb [6]. Imagine how dreadful it must be! 
Although phantom limb syndrome has been known since the sixteenth century, it was not until the 1990s that its symptoms were attributed to neuroplasticity-a maladaptive (a harmful) form of it.

There is one portion of the brain, called the somatosensory cortex (SSC), that is responsible for interpreting the world through the sense of touch. "Is the surface smooth?" and "Is the floor cold?" are questions that are answered by the SSC. The SSC is also responsible for something called proprioception. Before we explain what this word means, do the following experiment: close your eyes and try to touch the tip of your nose with the tip of your index finger. Did you do it? If so, you should be amazed by your superpower: you could do it without seeing the movement! This is proprioception-we know the position of our bodies and their parts, even with our eyes closed.

So, what happens when one loses a limb by amputation? Does the region inside the SSC responsible for that limb stop working? Usually, the brain area only slows down its function, but sometimes things go wrong, and the brain area responsible for the missing limb becomes hyperactive. How can it be hyperactive if the limb is missing?

In cases of leg amputation, neuroplasticity allows the neighboring areas in the SSC, such as the one in charge of the thigh, to take control of the missing leg area. One possible explanation is that active neurons in the thigh area "discover" that a neighboring leg region is inactive and extend some of their fibers to connect to the inactive neurons. Figure 1 is an example of research conducted in our laboratory with amputees. We found that not only the representation areas of the intact and missing limbs were altered, but also that the myelination of some parts of the brain was reduced.

Okay, so neurons from the thigh move toward and connect to neurons in the missing-leg area-how can this neuroplasticity translate into a phantom sensation? Imagine that you can feel each fold of your clothes that touches your limbs, but even when you wear a bathing suit, you can still feel that your limbs are there, just by moving them. This means that the limb area in your brain is constantly being activated. But in the case of amputation, when the neurons from the thigh and the lower leg become connected, both are activated when there is something stimulating the thigh skin. Thus, a touch to the thigh triggers a sensation of touch in the missing leg. The proprioceptive sensation in the thigh caused by moving may also trigger a proprioceptive sensation in the missing leg.

In other words, the brain (or at least the SSC) misunderstands the sensory experience, believing that the missing limb is still there. 
Figure 1

Neuroplasticity in a left leg amputee. The girl who lost her left leg was gently stimulated with a brush in three places: (1) the stump; (2) the same region of the intact leg; and (3) the remaining foot. The colored spots on the brain images indicate which regions were most active when the brush touched her skin In (1), you can see that the stimulation of the stump produces a larger area of activation than when the brush touches the thigh of the intact leg (2). In addition, stimulation of the stump seems to activate similar regions as when the foot is stimulated (3), but the areas are smaller. Notice that the left parts of the body are represented in the right side of the brain, and vice-versa. S1,

Somatosensory Area; M1, Motor Area; and M2, Supplementary Motor Area. Illustration by Julio Xerfan.

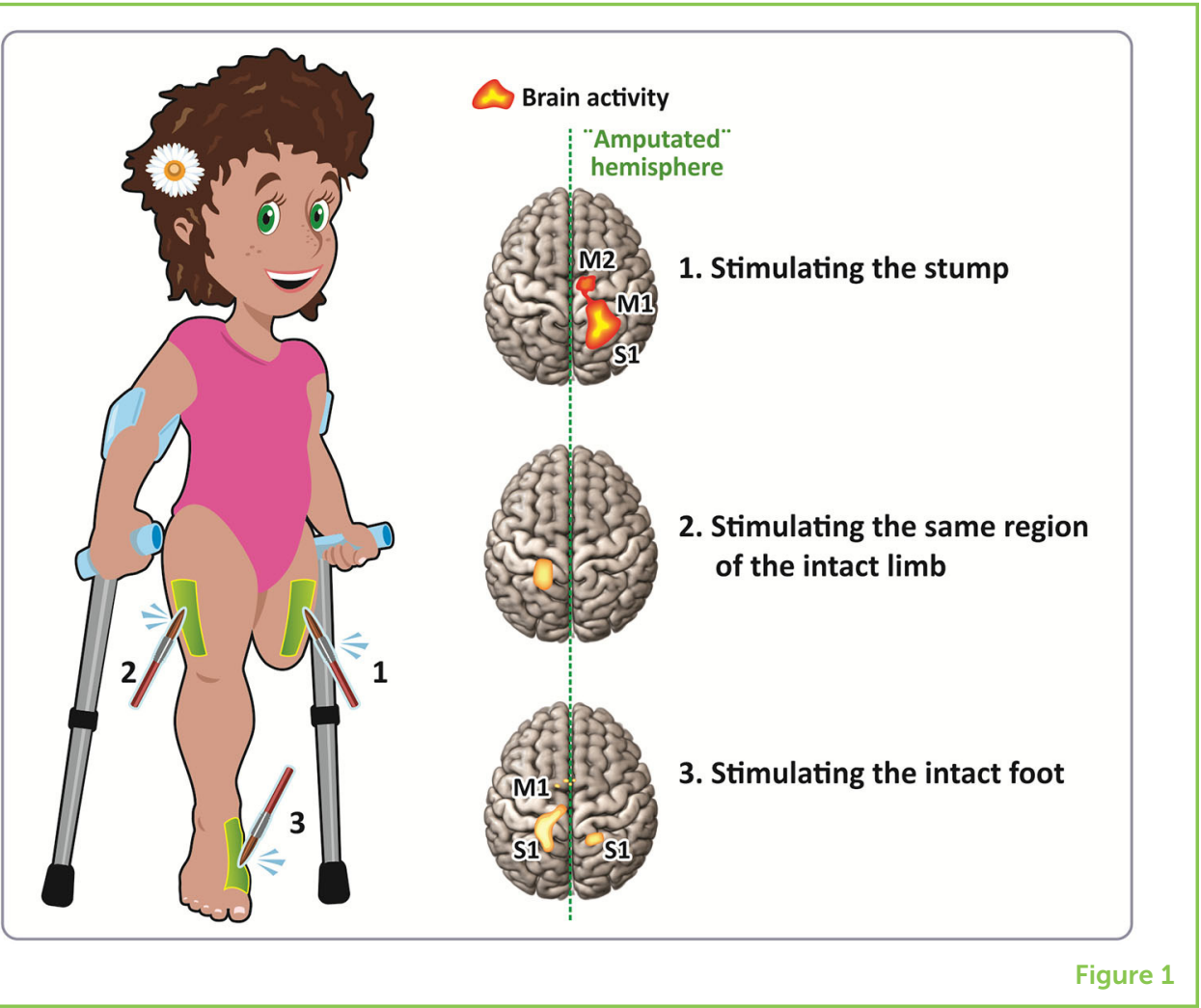

\section{CONCLUSION}

We have discussed two cases of neuroplasticity: one good and one harmful. We learned that, early in our lives, there are time windows during which neuroplasticity and development of some brain regions are very important. Such is the case for myelination of the mPFC, which is greatly dependent on our social experiences. As an example of harmful neuroplasticity, we learned that, in the event of an amputation, the brain might not realize that the limb is gone. This means that the parts of the brain that were responsible for interpreting signals coming from that limb (for example, the sensation of touch) will remain active, leading to phantom limb syndrome. Overall, from these two examples, you can see that the brain is not static, it is constantly responding to challenges. Every piece of information we learn or every person we meet can lead to lasting effects in our brain and our lives.

\section{ACKNOWLEDGMENTS}

We thank for the real human brain images of the figure, provided by our colleague Theo Marins.

\section{REFERENCES}

1. Goh, J. O., and Park, D. C. 2009. Neuroplasticity and cognitive aging: the scaffolding theory of aging and cognition. Restor. Neurol. Neurosci. 27:391-403. doi: 10.3233/RNN-2009-0493 
2. Gutchess, A. 2014. Plasticity of the aging brain: new directions in cognitive neuroscience. Science 346:579-82. doi: 10.1126/science.1254604

3. Brown, A., and Weaver, L. C. 2012. The dark side of neuroplasticity. Exp. Neurol. 235:133-41. doi: 10.1016/j.expneurol.2011.11.004

4. Fuhrmann, D., Knoll, L. J., and Blakemore, S. J. 2015. Adolescence as a sensitive period of brain development. Trends Cogn. Sci. 19:558-66. doi: 10.1016/ j.tics.2015.07.008

5. Makinodan, M., Rosen, K. M., Ito, S., and Corfas, G. 2012. A critical period for social experience-dependent oligodendrocyte maturation and myelination. Science 337:1357-60. doi: 10.1126/science.1220845

6. Simões, E. L., Bramati, I., Rodrigues, E., Franzoi, A., Moll, J., Lent, R., et al. 2012. Functional expansion of sensorimotor representation and structural reorganization of callosal connections in lower limb amputees. J. Neurosci. 32:3211-20. doi: 10.1523/JNEUROSCI.4592-11.2012

SUBMITTED: 22 December 2019; ACCEPTED: 06 October 2020; PUBLISHED ONLINE: 12 November 2020.

EDITED BY: Lauren Jantzie, Johns Hopkins University, United States

CITATION: Guimarães DM, Valério-Gomes B and Lent R (2020) Neuroplasticity: The Brain Changes Over Time! Front. Young Minds 8:522413. doi: 10.3389/frym. 2020.522413

CONFLICT OF INTEREST: The authors declare that the research was conducted in the absence of any commercial or financial relationships that could be construed as a potential conflict of interest.

COPYRIGHT @ 2020 Guimarães, Valério-Gomes and Lent. This is an open-access article distributed under the terms of the Creative Commons Attribution License (CC BY). The use, distribution or reproduction in other forums is permitted, provided the original author(s) and the copyright owner(s) are credited and that the original publication in this journal is cited, in accordance with accepted academic practice. No use, distribution or reproduction is permitted which does not comply with these terms.

\section{YOUNG REVIEWERS}

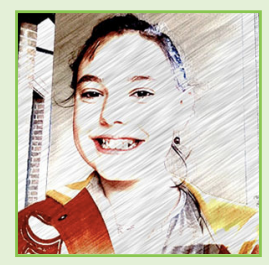

\section{ASHLEY, AGE: 12}

Hi I am Ashley!! I like to dance flamenco everyday because it is fun and is a great physical activity. Flamenco and acting class are my favorite classes this year. I go to a school that focuses not just on normal classes, but on performing arts as well. In my spare time I like making jokes and playing card games with my family. 

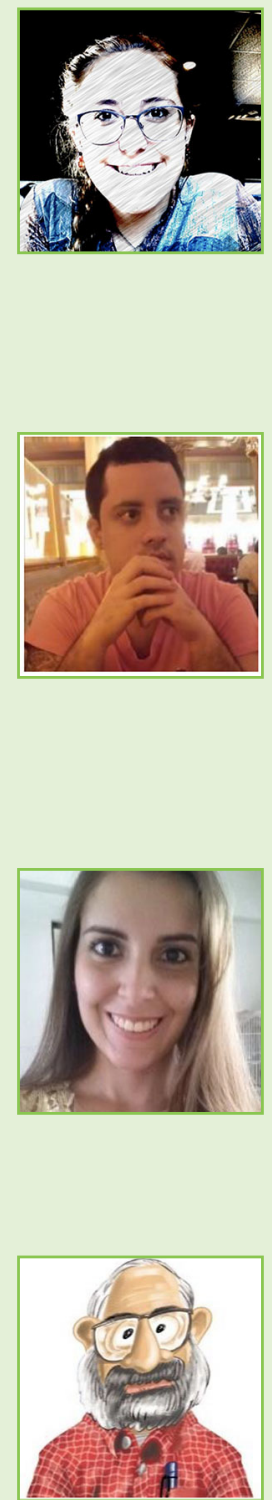

\section{SAMANTHA, AGE: 15}

Hi my name is Samantha! I like to read and write, and I am working on writing a long story right now. My favorite classes are Chemistry and English. In my free time I enjoy contemplating the mysteries of the universe, staring off into space, and writing stories.

\section{AUTHORS}

\section{DANIEL MENEZES GUIMARÃES}

I am a Brazilian Post-doctoral Associate, now working in Canada. I have been working in the field of neuroscience for more than 5 years. Since my teenage years, I have been fascinated with the brain and its workings. When I enrolled in grad school, I dedicated myself to understanding how the brain interprets the social world. My research is focused on the social behavior of animals in social isolation (one of the examples in this article). Aside from science, I am a musician (electric guitar) and I also write poetry. *danielmgui@gmail.com

\section{BRUNA VALÉRIO-GOMES}

I am a Post-doctoral Associate in Brazil. My primary interest is understanding the neural basis of diseases, and how human behavior is affected by them. I have focused on studying a brain cell called the oligodendrocyte, its functions and how it interacts with other cells in disease conditions. I want to enhance my understanding of psychiatric diseases by studying not only their neural basis but also their social and psychological aspects. Also, I am interested in aesthetics, fashion, and games.

\section{ROBERTO LENT}

I am a Professor of Neuroscience at the Federal University of Rio de Janeiro and head the lab where Daniel and Bruna did their graduate work. I supervised their work, but I loved when they did not entirely follow my suggestions, because their options usually turned out to be better than my suggestions. 